\title{
Experimental investigation on the fracture behaviour of natural stone exposed to monotonic and cyclic loading
}

\author{
Andrea Spagnoli \\ Department of Engineering and Architecture, Università di Parma, Parma, Italy \\ spagnoli@unipr.it, bttp:/ /orcid.org/0000-0002-0592-7003 \\ David A. Cendon Franco \\ Departamento de Ciencia de los Materiales, Universidad Politécnica de Madrid, Madrid, Spain \\ dcendon@mater.upm.es,bttp://orcid.org/0000-0001-7256-0814
}

Antonio D'Angelo

Department of Engineering and Architecture, Università di Parma, Parma, Italy

dangeloa@pizzarotti.it, https://orcid.org/0000-0003-4704-1048

\begin{abstract}
The present paper is devoted to an experimental study on the fracture behaviour of natural stones, commonly used as elements for building cladding, under both monotonic and cyclic loading, with particular emphasis to white Carrara marble. The effect of progressive damage produced by inservice thermal fluctuations can be investigated through the application of appropriate cyclic mechanical loads. In the experimental tests conducted, some static mechanical properties of marble are characterized by means of three-point bending tests on edge-cracked prismatic specimens for the determination of Young's modulus, tensile strength and fracture energy. Moreover, cyclic three-point bending tests are conducted to determine the propagation rate of nominally Mode-I fatigue cracks. Finally, the fatigue behaviour of the marble is studied through a cohesive crack model, in which the direct tensile strength of the material is determined by a Brazilian test, and the behaviour is calibrated by means of a suitable FE model. The effect of crack path on the fracture resistance of marble is discussed.
\end{abstract}

KEYWORDS. Fatigue crack propagation; Marble; Quasi-brittle behaviour, Thermal cycles.

\section{OPEN ACCESS}

Citation: Spagnoli, A., Cendon Franco, D. A., D'Angelo, A., Experimental investigation on the fracture behaviour of natural stone exposed to monotonic and cyclic loading, Frattura ed Integrità Strutturale, 47 (2019) $394-400$.

Received: 25.10 .2018

Accepted: 12.11 .2018

Published: 01.01.2019

Copyright: (C) 2019 This is an open access article under the terms of the CC-BY 4.0, which permits unrestricted use, distribution, and reproduction in any medium, provided the original author and source are credited.

\section{INTRODUCTION}

$\mathrm{T}$ he Carrara marble is a widely used material in the construction field, both in historical and monumental buildings and in recent constructions, for example in the cladding elements of ventilated facades [1]. Installed as coating of facades, the marble slabs are exposed to different actions that deteriorate the material, including temperature (daily 
and seasonal excursions, through-thickness gradient), mechanical loads (wind, self-weight), chemical attacks (acid rain) and humidity changes. In particular, temperature may induce stresses due to thermal expansion (restraint effects of the anchorage system, non linear temperature fields and non uniform thermal expansion) and thermal fluctuations tend to cause a progressive damage of the material, sometimes accompanied by a curvature of the surface of the slabs [2]. Such bowing phenomenon can progress up to the collapse of the element, with consequences often critical on safety for the users of the buildings where these covering slabs are installed. Bowing is generally accompanied by an overall reduction of strength, which increases with increase in degree of bowing, while at the micro structural level of the material bowing is accompanied by a decohesion of calcite grains.

The present paper is devoted to an experimental study on the fracture behaviour of natural stones under both monotonic and cyclic loading, with particular emphasis to white Carrara marble. The effect of progressive damage produced by thermal fluctuations can be investigated through the application of appropriate cyclic mechanical loads. In the experimental tests conducted, some static mechanical properties of marble are characterized by means of three-point bending tests on edgecracked prismatic specimens for the determination of Young's modulus, tensile strength and fracture energy [3]. Moreover, cyclic three-point bending tests are conducted to determine the propagation rate of nominally Mode-I fatigue cracks [4]. Finally, the fatigue behaviour of the marble is studied through a cohesive crack model, in which the direct tensile strength of the material is determined by a Brazilian test, and the behaviour is calibrated by means of a suitable FE model [5]. The effect of crack path on the fracture resistance of marble is discussed. In particular, it is shown that different level of meandering in the intergranular cracking of marble is observed and correlated with the so-called xenoblastic or homoblastic texture of calcite grains [4].

\section{EXPERIMENTAL TESTING UNDER MONOTONIC LOADING}

A preliminary experimental campaign is carried out to quantify the resistance parameters of a Carrara marble under monotonic loading. Four prismatic specimens were tested under three-point bending. The nominal dimensions of the specimens are as follows: length $L=220 \mathrm{~mm}$; span $S=180 \mathrm{~mm}$; height $W=60 \mathrm{~mm}$; width $B=30 \mathrm{~mm}$ (Fig. 1). One specimen out of the 4 ones is a smooth specimen. Notched specimens are characterised by a central edge notch machined by means of a water jet technique. Notches with different nominal dimensions are machined, so that the notch depth is between $6.9 \mathrm{~mm}$ and $8.1 \mathrm{~mm}$ (the notch width is kept equal to $1.5 \mathrm{~mm}$ due to some technical constraints). Tests were performed by means of an Instron testing machine. Three LVDT sensors were used to measure the rigid body motionfree mid-span deflection of the beam and a clip-on gauge to measure Crack Mouth Opening Displacement (CMOD). Tests on notched specimens were performed under CMOD control with a of less than $10^{-3} \mathrm{~mm} / \mathrm{min}$. Digital image correlation technique was adopted to capture full-field two-dimensional displacement maps on specimen surface in the notch vicinity.

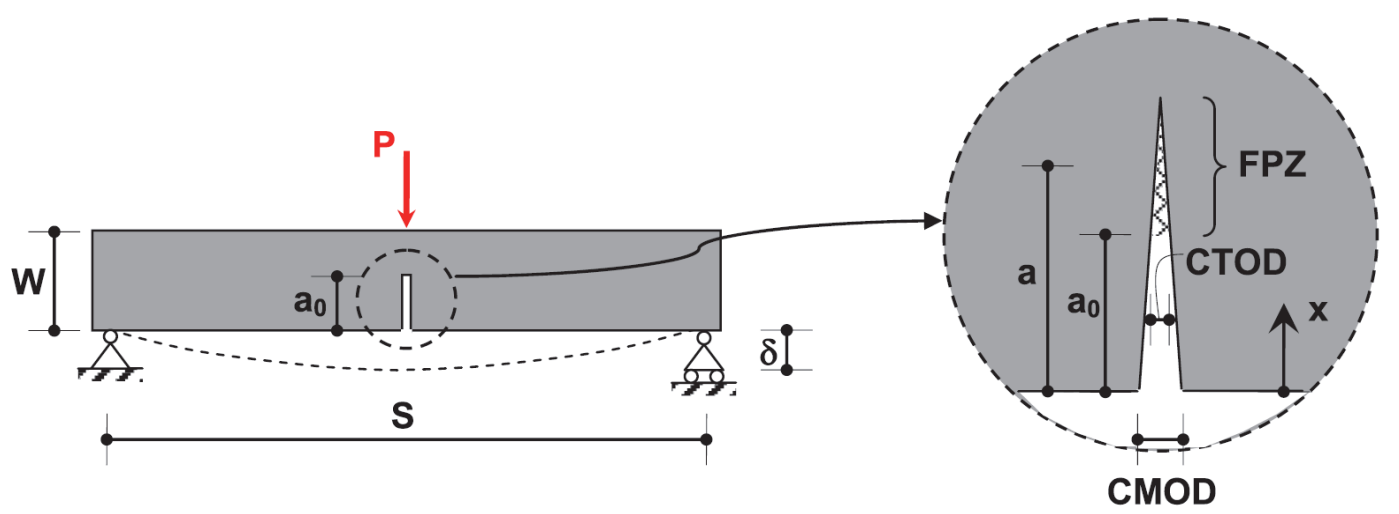

Figure 1: Geometrical and testing configuration of notched specimen under three-point bend loading.

The rupture load of the smooth specimen is equal to $5.1 \mathrm{kN}$ (corresponding to a nominal bending strength of $12.8 \mathrm{MPa}$, where the nominal stress $\sigma_{N}$ is equal to $\left.6 P S /\left(4 B W^{2}\right)\right)$.

For the 3 notched specimens, the mean bending stress at failure is equal to $6.7 \mathrm{MPa}$ (corresponding to a mean rupture load of $2.7 \mathrm{kN}$ ), with a coefficient of variation equal to 0.13 . In Fig. 2, the load against mid-span deflection is shown for two notched specimens, along with the corresponding curves of the nominal stress against the crack mouth opening displacement. 
From the experimental curves related to notched specimens, fracture toughness of marble is calculated by using two different approaches. The first approach is based on the two-parameter model [6]. Note that a modified version of the twoparameter model has recently been proposed in order to take into account the possible crack deflection during the stable crack propagation [7-9]. Accordingly, the initial crack length $\mathrm{a}_{0}$ is assumed to grow steadily before the peak load is attained. This nonlinear stable stage terminates when the crack propagates to a critical extent and the SIF $K_{I}$ attains a value $K_{\text {sIC }}$ that differs from the nominal $K_{I C}$ (computed on the basis of $a_{0}$ ). If the geometric and loading conditions are such that the stress intensity factor is monotonically increasing with the crack length (being the load constant), as occurs in the case of a 3-point bend beam with an edge crack, the critical condition explained before takes place at the peak load. From LEFM formulas and from two compliance experimental measurements, the equivalent crack length and the effective toughness $K_{s I C}$ are worked out. The second approach is based on the work-of-fracture method in Ref. [10] recommended by the RILEM technical committee. For 3-point bending tests on edge-notched beams, the method is based on the experimental determination of the work exerted by the applied mid-span force, which corresponds to the area underneath the complete load-displacement curve. Such a work is assumed to be fully spent to produce a mode I crack through the mid-span ligament of the beam.

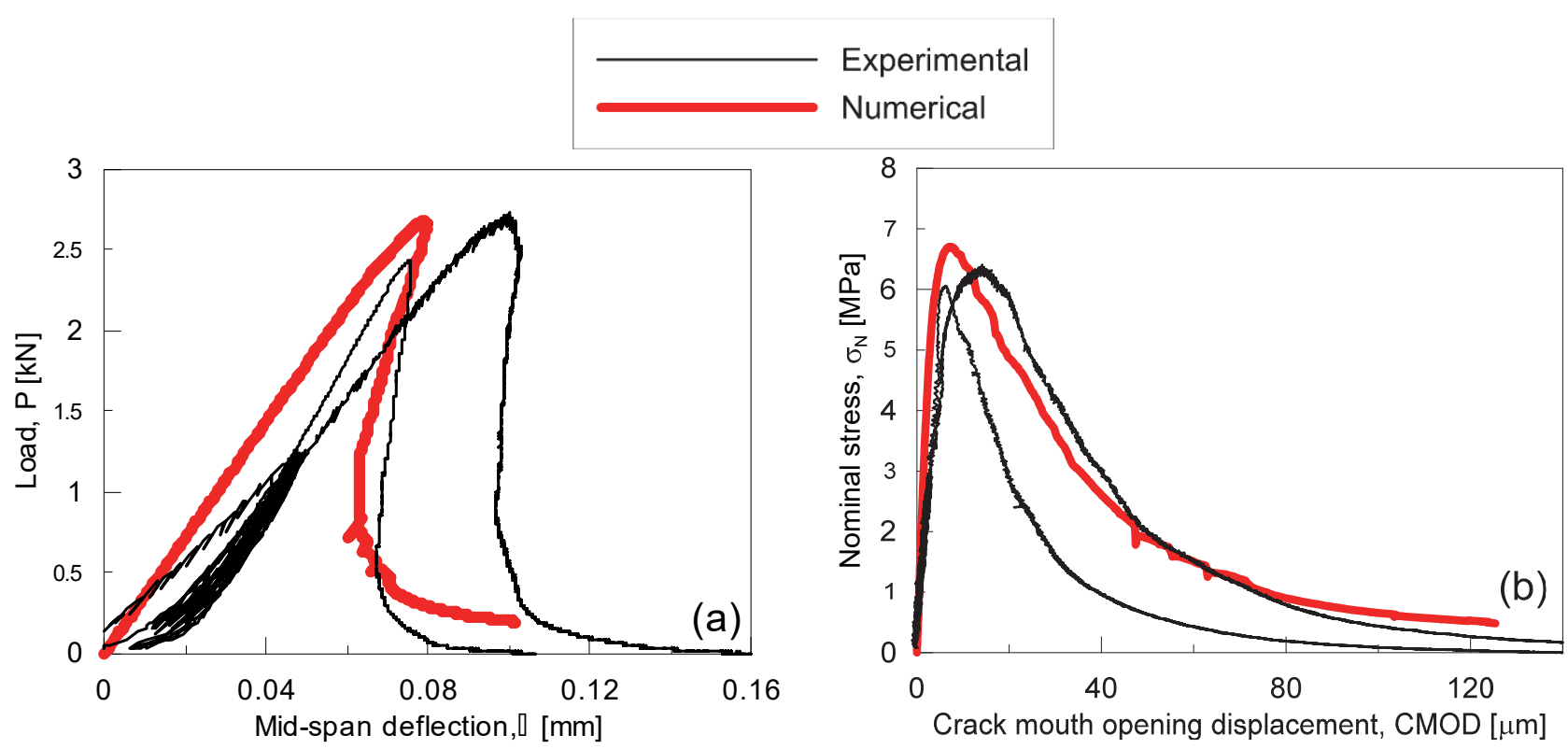

Figure 2: Load vs mid-span deflection curves (a) and nominal stress-CMOD curves (b) for notched specimens under three-point bending. In the graph experimental results for two specimens (black thin lines) are reported along with numerical results (red thick lines).

The mean value of fracture toughness according to the two-parameter model is equal to $1.90 \mathrm{MPam}^{0.5}$ (coefficient of variation equal to 0.19). According to the work-of-fracture method, the mean fracture toughness is $1.91 \mathrm{MPam}^{0.5}$ (coefficient of variation equal to 0.37 ).

For the sake of completeness, a splitting test on four prismatic specimens (nominal dimensions $D=60 \mathrm{~mm}, L=30 \mathrm{~mm}$, $B=60 \mathrm{~mm})$ was performed according to ASTM C496. The resulting indirect tensile strength $\left(\sigma_{t}=2 P /(\pi D L)\right)$ is equal on average to $7.1 \mathrm{MPa}$ (coefficient of variation equal to 0.11 ).

\section{EXPERIMENTAL TESTING UNDER CYCLIC LOADING}

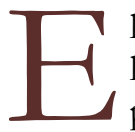
leven three-point bending tests on notched specimens, with the same geometry as that adopted for monotonic loading and with the initial notch length $a_{0}$ in the range 6.6 to $8.5 \mathrm{~mm}$, under nearly pulsating loading were performed. Tests were carried out under load control mode, with blocks of cycles composed by a single square cycle with frequency of $0.1 \mathrm{~Hz}$ and by 125 sinusoidal cycles with frequency $2.5 \mathrm{~Hz}$. Square cycles are introduced to take DIC photos at maximum load. Applied cycles have a loading ratio $\mathrm{R}=0.1$ and a maximum load expressed as a percentage of the mean failure load $P_{u}$ of three-point bend notched specimens under monotonic loading $\left(P_{u}=2.7 \mathrm{kN}\right)$. SN-like data are 
reported in Fig. 3, where the load range level is expressed as the range of the applied SIF (calculated for a crack length equal to $a_{0}$ ), normalized by the estimated SIF threshold $\Delta K_{I, t h}=0.74 \mathrm{MPam}^{0.5}$ (see the last paragraph of the present Section). Run-out specimens (see open circle in Fig. 3) correspond to unbroken specimens after a number of loading cycles larger than $N_{0}=100,000$. A log-log linear fitting of the experimental points with $N_{f}<N_{0}$ is attempted (negative inverse slope of 50), bearing in mind that the paucity of experimental data, along with the inherent scatter of the material properties, do not allow us to draw any conclusion on the behavioural trend observed.

For illustrative purposes, Fig. 4a shows the experimental curve of the CMOD at maximum load in the loading cycle against the number of cycles to failure for a notched specimen loaded with a ratio $\Delta K_{I} / \Delta K_{I, t h}=1.16$. By means of classical LEFM formulas, by knowledge of the applied load and the Young modulus of the marble under investigation, the effective crack length can be calculated from the measured CMOD. Consequently, crack length against number of cycles to failure curves can be obtained (see red curve in Fig. 4a).

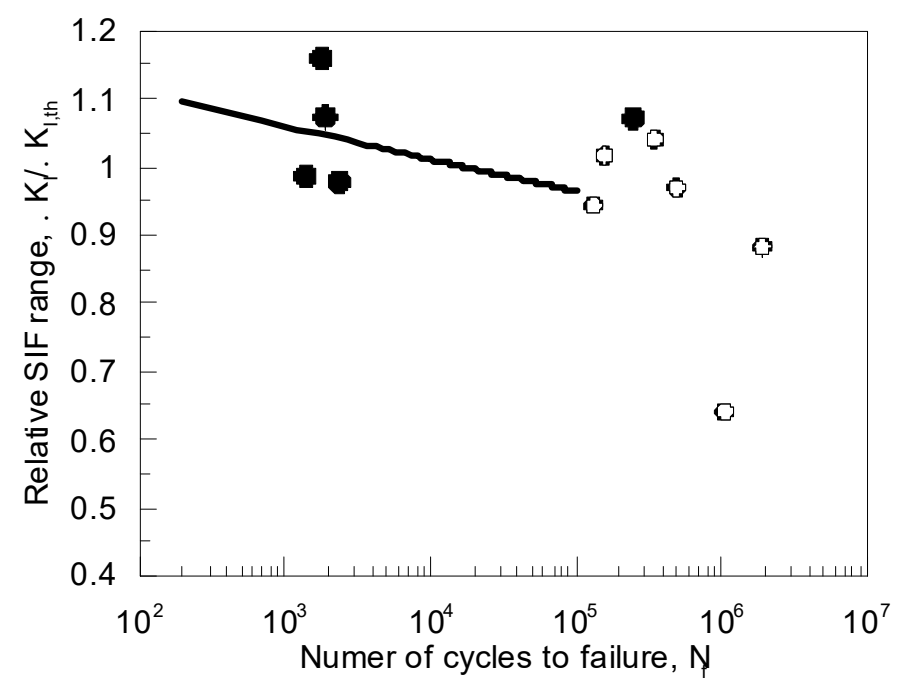

Figure 3: SN plot of fatigue results on notched specimens (open circles indicate run-out data).

The experimental fatigue crack growth results, now expressed in terms of crack length $a$ versus number of loading cycles, are analysed. In particular, the material parameters $C$ and $m$ of the Paris law $\left(d a / d N=C \Delta K_{I}^{m}\right)$ are estimated. Such a law has been proved to describe well the experimental trend of the fatigue growth of the so-called long cracks for a variety of engineering materials with particular regards to metals. For this purpose, the crack growth rate da/dN versus number of cycles is determined according to ASTM E647 standard. The experimental $\mathrm{d} a / \mathrm{d} N-N$ data are analyzed by an incremental polynomial method. This method for computing $\mathrm{da} / \mathrm{dN}$ involves fitting a second-order polynomial (parabola) to sets of $(2 \mathrm{n}+1)$ successive data points a-N, where $n$ is usually $1,2,3$, or $4(n=4$ is assumed here). The rate of crack growth at each central point $a_{\mathrm{i}}$, in the range $a_{\mathrm{i}-\mathrm{n}}-a_{\mathrm{i}+\mathrm{n}}$, is obtained from the derivative of the above parabola. The SIF range $\Delta K_{I}$ is determined according to classical LEFM expression for the current crack length $a$. As an example, in Fig. $4 \mathrm{~b}$ the $\mathrm{d} a / \mathrm{dN}-\Delta K_{I}$ plot is reported for the same specimen of Fig. $4 \mathrm{a}$.

The mean values based on five experimental tests of the estimated parameters of the Paris law are $C=0.0002$ and $m=3.3$ expressing $\mathrm{d} a / \mathrm{dN}$ as $\mathrm{m} /$ cycle and $\Delta K_{I}$ as $\mathrm{MPam}^{0.5}$, although a large scatter in the results is recorded (coefficient of variation of $C$ and $m$ is equal to 0.34 and 0.80 , respectively), and a degree of arbitrariness is introduced in the selection of the range of Paris law validity for best-fitting of experimental data point. The obtained values are in line with those reported in Ref. [4] $(C=0.00029$ and $m=3.9)$.

Finally, by considering the run-out fatigue tests on notched specimens (considering a conventional number of cycles for the fatigue limit $N_{0}=100,000$ ), an estimation of a fatigue limit for the marble under investigation is attempted. In particular, a threshold condition in terms of SIF range (related to the initial notch length $a_{0}$ ) is obtained. The resulting mean value of $\Delta K_{t b}$ is $0.74 \mathrm{MPam}^{0.5}$ for loading ratio $\mathrm{R}=0.1\left(K_{I \text { max }, t h}=\Delta K_{I, t h} /(1-\mathrm{R})=0.83 \mathrm{MPam} \mathrm{m}^{0.5}\right)$. It is instructive to note that the ratio $K_{I \text { max } x \text { th }} / K_{s I C}$ is equal to 0.44 , which indicates a behavior slightly in the range of fatigue insensitive materials with flaws according to the seminal work of Fleck et al [11]. 

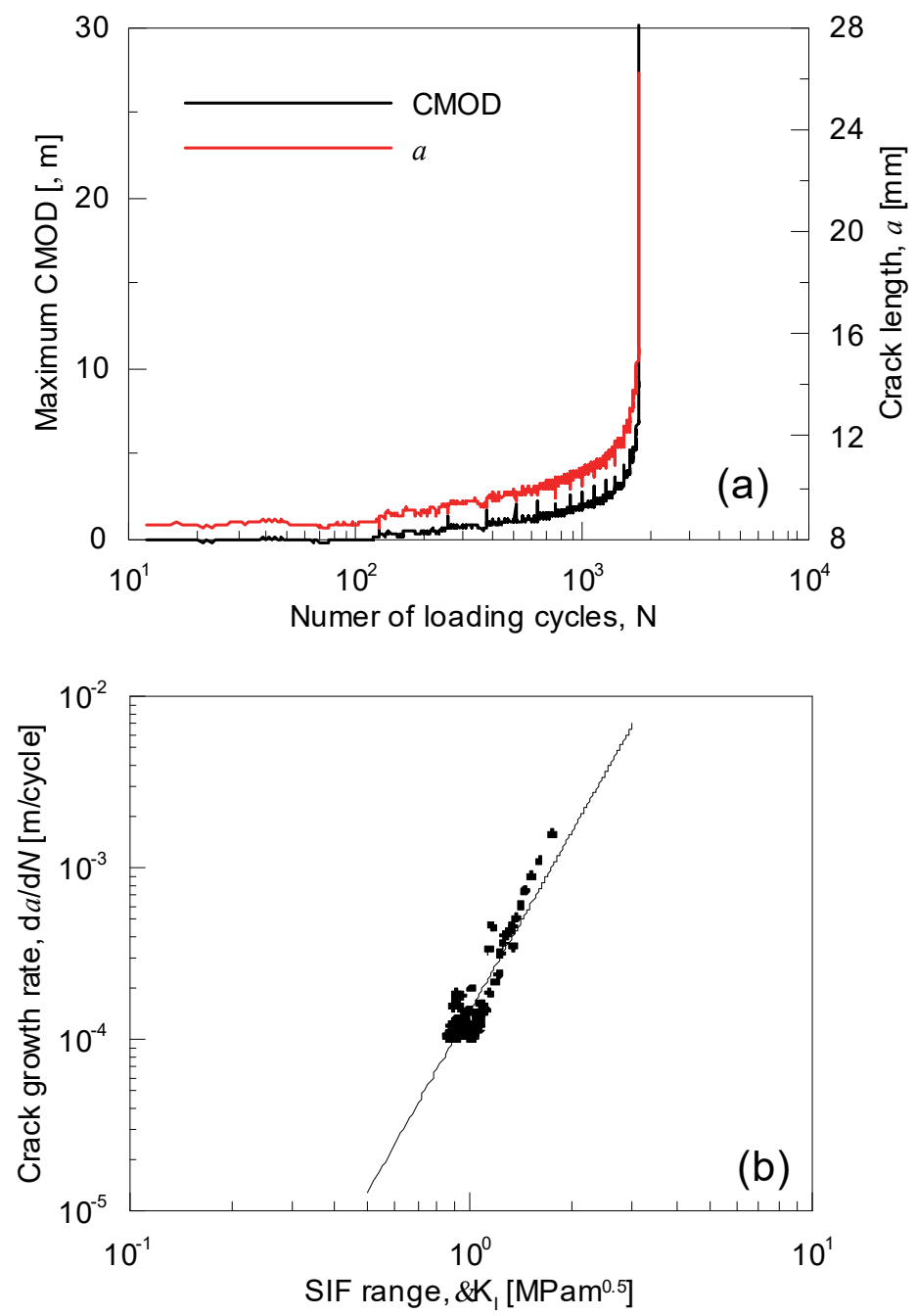

Figure 4: Fatigue crack growth data (a) and d $a / \mathrm{d} N-\Delta K_{I}$ plot (b) for a notched specimen with $\Delta K_{I} / \Delta K_{I, t h}=1.16$.

\section{NUMERICAL ANALYSIS}

$\mathrm{I}$ $\mathrm{n}$ order to analyze the results from a meso-mechanics point of view, a numerical simulation based on the Cohesive Zone Model (CZM) was conducted. The CZM was firstly proposed for the numerical simulation of fracture of quasibrittle materials, such as concrete and rocks by Hillerborg and coworkers [12]. The evolution of damage in CZM is accounted for by means of the so-called softening curve, which is the mathematical function relating the mode I crack opening displacement, $w$, with the stress transferred across the crack lips, $\sigma$ (see Fig. 5).
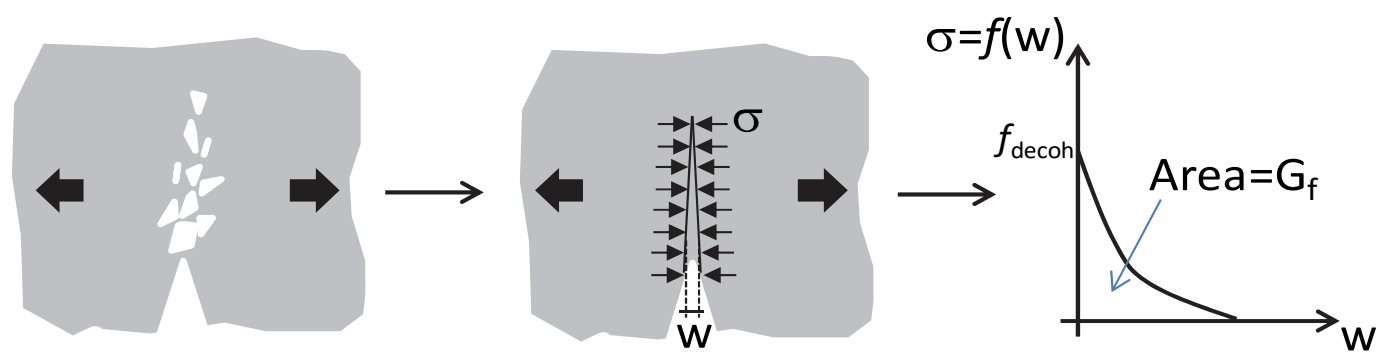

Figure 5: Meso-mechanics basis of the Cohesive Zone Model and parameters of the softening curve. 
The softening curve is defined by three main ingredients: the decohesion strength, $f_{\text {decoh, }}$ which is the value of the softening curve for null crack opening; the area comprised between the curve and the abscissa axis, which represents the specific fracture energy of the material, $G_{\mathrm{F}}$; and the shape of the softening curve, which depends on the way in which the material is damaged as the crack is opened. In the numerical simulations presented in this paper, the CZM was implemented in combination with the embedded crack approach. Further details about the implementation can be found in [13, 14].

When applying the CZM to quasi-brittle materials, the decohesion strength is usually set equal to the tensile strength of the material measured through a splitting tensile test [15], which according to the experimental campaign previously detailed was equal to $f_{\mathrm{t}}=7.1 \mathrm{MPa}$ (Young modulus was taken as $\mathrm{E}=75 \mathrm{GPa}$ ). About the area under the softening curve, it was set equal to the specific fracture energy determined in the three-point-bending tests under static conditions, that is to say, $G_{\mathrm{F}}=$ $60 \mathrm{~N} / \mathrm{m}$, considering the results of two experimental tests reported in Fig. 2.

Unfortunately, up to date no general procedure has been set to determine the shape of the softening curve for a given material. There are some standard curves, such as the bi-linear curve for plain concrete [16], or the rectangular curve for steels [17] but to the authors' knowledge, no standard has been set in the case of marble. For this reason, a trial-and-error procedure was made by numerical simulation of the three-point-bending tests conducted for the determination of the specific fracture energy, trying different softening curve shapes until achieving a good agreement with the experimental results. To facilitate this trial-and-error process, according to [18], the following family of softening curves was used: $f^{*}(\xi)=1-\xi e^{n} /\left[1+\xi\left(e^{n}-1\right)\right]$, where $f^{*}$ is the non-dimensional stress transferred across the crack lips (stress divided by the decohesion strength), $\xi$ is the non-dimensional crack opening (crack opening divided by the critical crack opening) and $n$ is a material constant. With this family of curves it is possible to modify the shape of the softening curve by playing with the $n$ parameter $(n=0$ leads to a linear softening curve). In the case of the marble analyzed in this paper, it was found that a value of $n=2$ leads to a reasonable agreement between the experimental behaviour and the numerical prediction, as is shown in Fig. 2.

The numerical simulation of the three-point-bending static tests allowed us to provide a meso-mechanics insight on the results of cyclic loading tests. In quasi-brittle materials, it has been demonstrated that for samples having dimensions of the order of magnitude of the size of the Fracture Process Zone (FPZ), the peak load is reached after such an FPZ has been largely developed ahead of the notch tip of the specimen. Thanks to the CZM, it is possible to analyze the initiation and evolution of the FPZ, since it is equivalent to the cohesive zone. Fig. 6 shows the length of the cohesive zone (FPZ) as a function of the nominal stress intensity factor, $\mathrm{K}_{\mathrm{I}}$, applied during the simulation of the three-point bending static test. In this plot the $\mathrm{K}_{\mathrm{I}}$ required to initiate the FPZ is marked, which is considerably lower than the $\mathrm{K}_{\mathrm{I}}$ corresponding to the peak load. In the same plot, the $\Delta \mathrm{K}_{\mathrm{I}}$ corresponding to the fatigue propagation threshold is also highlighted. It can be seen how the latter is mostly inside the region of FPZ generation, revealing that a significant level of damage (corresponding to a large FPZ) ahead of the notch tip is required for fatigue crack propagation. Actually, according to this analysis, those $\Delta \mathrm{K}_{\mathrm{I}}$ ranges below the threshold represented in the figure would not lead to crack propagation in spite of causing appreciable damage (FPZ) at the notch tip. It must be reminded that this result is solely based on a numerical simulation, requiring further experimental data to confirm the hypothesis.

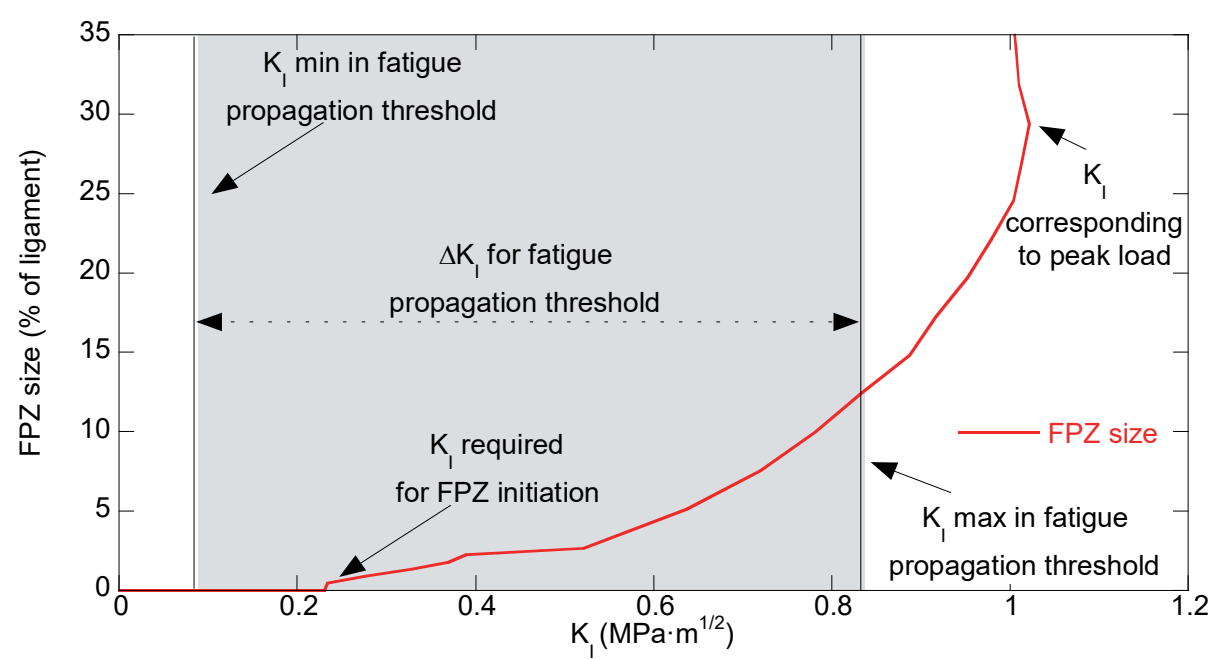

Figure 6: Fracture process zone (FPZ) size in terms of \% of the ligament as a function of the stress intensity $\mathrm{K}_{\mathrm{I}}$ applied. The figure also shows the $\Delta \mathrm{K}_{\mathrm{I}}$ corresponding to the fatigue crack propagation threshold. 


\section{CONCLUSIONS}

A $\mathrm{n}$ experimental campaign on the fracture behavior of Carrara marble under monotonic and cyclic loading has been carried out. The results under monotonic loading show a well-known quasi-brittle behavior of the material, which requires for instance a two-parameter approach to correctly estimate fracture toughness. The results under cyclic loading allow us to estimate the material parameters governing the fatigue crack growth. Also, such results allow an attempt to estimate a fatigue limit in terms of SIF threshold. A comparison of experimental monotonic results with those of a numerical model based on a cohesive crack approach shows a good correlation. Finally, the numerical results permit to give an insight on the correlation between FPZ and fatigue threshold conditions. Further investigation is needed to fully understand the experimental observation under cyclic temperature of the different behavior of marble depending on the microstructural texture of calcite grains (see xenoblastic and homoblastic types of marble) and in turns on the roughness features of intergranular cracking profiles.

\section{REFERENCES}

[1] Ferrero, A.M., Migliazza, M., Spagnoli, A. Theoretical modelling of bowing in cracked marble slabs under cyclic thermal loading (2009) Construction and Building Materials, 23 (6), pp. 2151-2159.

[2] Spagnoli, A., Ferrero, A.M., Migliazza, M. A micromechanical model to describe thermal fatigue and bowing of marble (2011) International Journal of Solids and Structures, 48 (18), pp. 2557-2564.

[3] Spagnoli, A., Carpinteri, A., Ferretti, D., Vantadori, S. An experimental investigation on the quasi-brittle fracture of marble rocks (2016) Fatigue and Fracture of Engineering Materials and Structures, 39 (8), pp. 956-968.

[4] Migliazza, M., Ferrero, A.M., Spagnoli, A. Experimental investigation on crack propagation in Carrara marble subjected to cyclic loads (2011) International Journal of Rock Mechanics and Mining Sciences, 48 (6), pp. 1038-1044.

[5] Cendon, D. A., Torabi, A. R., Elices, M. Fracture assessment of graphite V-notched and U-notched specimens by using the cohesive crack model (2015) Fatigue and Fracure of Engineering Materials and Structures, 38 (5), pp. 563-573.

[6] Jenq, Y. and Shah, S. P. (1985) Two parameter fracture model for concrete. J. Eng. Mech., 111, 1227-1241.

[7] Carpinteri, A., Berto, F., Fortese, G., Ronchei, C., Scorza, D., Vantadori, S. (2017), Modified two-parameter fracture model for bone. Engineering Fracture Mechanics, 174, 44-53, DOI: 10.1016/j.engfracmech.2016.11.002.

[8] Carpinteri, A., Fortese, G., Ronchei, C., Scorza, D., Vantadori, S. (2017), Mode I fracture toughness of fibre reinforced concrete, Theoretical and Applied Fracture Mechanics, 91, 66-75, DOI: 10.1016/j.tafmec.2017.03.015.

[9] Vantadori, S., Carpinteri, A., Guo, L.-P., Ronchei, C., Zanichelli, A. (2018), Synergy assessment of hybrid reinforcements in concrete, Composites Part B: Engineering, 147, 197-206, DOI: 10.1016/j.compositesb.2018.04.020.

[10] Bazant, Z. P. (1996) Analysis of work-of-fracture method for measuring fracture energy of concrete. J. Eng. Mech. ASCE, 122, 138-144.

[11] Fleck, N. A., K. J. Kang, and M. F. Ashby. (1994). Overview No. 112: The cyclic properties of engineering materials. Acta Metallurgica et Materialia 42(2), pp. 365-381.

[12] Hillerborg, A., Modéer, M., and Petersson, P. (1976). Analysis of crack formation and crack growth in concrete by means of fracture mechanics and finite elements, Cement and Concrete Res. 6.

[13] Sancho, J.M., Planas, J., Cendón, D.A., Reyes, E., Gálvez, J.C. (2007). An embedded crack model for finite element analysis of concrete fracture. Eng. Fract. Mech., 74, pp. 75-86.

[14] Cendón, D.A., Torabi, A.R. and Elices, M. (2015). Fracture assessment of graphite V- and U- notched specimens by using the cohesive crack model. Fat. and Fract. of Eng. Mats and Structures, 38-5, pp. 563-573.

[15] Bazant, Z.P. and Planas, J. (1998). Fracture and size effect in concrete and other quasibrittle materials. CRC Press. Boca Raton, Florida.

[16] Guinea, G.V., Planas, J. and Elices, M. (1994). A general bilinear fit for the softening curve of concrete. Materials and structures 27 (2), pp. 99-105.

[17] Dugdale, D.S. (1960), Yielding of steel sheets containing slits. J. Mech. Phys. Solids, 8, pp. 100.

[18] Cendón, D.A., Jin, N., Liu, Y., Berto, F. and Elices, M. (2017). Numerical Assessment of Gray Cast Iron Notched Specimens by Using a Triaxiality-Dependent Cohesive Zone Model. Theoretical and Applied Fracture Mechanics 90, pp. 259-267. 